\title{
KONSEP OTORITAS DAN OTORITARIANISME PENAFSIRAN KHÂLED M. ABOU EL-FADL
}

\author{
Ahmad Fakhruddin Fajrul Islam \\ Institut Agama Islam Bani Fattah Jombang, Indonesia \\ E-mail: fahdin_adin@yahoo.com
}

\begin{abstract}
Today, the anxiety of the authorities in the name of religion is an issue of interest to the talk. This is due to increasingly widespread and growing ideology of fundamentalism in the Islamic world. As an academic who is very familiar with Islamic law, Abou al-Fadl admitted that Islamic law is the heart and core of the Islamic religion. However Abou alFadl just do not believe that the intellectual treasures were able to survive the onslaught of the trauma of colonialism and modernity. Even thought, the remnants of the treasures of classical Islamic law is on the brink of extinction. Rests on the idea, he wanted to 'revive' the tradition of classical Islamic law is quite dynamic, and has a base that is tolerant and pluralistic epistemology. If Mohammed Arkoun claims, that in Islamic thought, there is still something 'thoughtless', then, Abou el-Fadl want re-formulation of the treasures of Islamic thought, namely 'something that has been forgotten'.
\end{abstract}

Kaywords: Authority, Islamic Thought, Method Of Interpretation, Abou al-Fadl. 


\section{Pendahuluan}

Friedrich Nietzshe (1844-1900) dalam salah satu karyanya membuat ilustrasi orang gila yang mondar-mandir di pasar sambil berujar, "Tidakkah kita mendengar kesibukan para penggali kubur yang sedang mengubur Tuban? Apakah kita tidak mencium bau bangkai Tuban? Babkan Tuban telah menjadi busuk. Tuban mati. Tuban akan tetap mati, dan kita telah membunubnya". ${ }^{1}$ Ilustrasi Nietzshe yang memaklumatkan kematian Tuhan ini tentu bukan dalam arti yang sebenarnya, melainkan simbol kegelisahan terhadap bentuk kepercayaan nilai-nilai universal-absolut agama yang telah menyetubuhi kreativitas individu sebagai objek yang tak berdaya.

Potret historis menunjukkan semenjak tahun 1546 agama Kristen (Katolik) dengan lembaga gerejanya telah menjelma menjadi institusi otoriter yang paling berkuasa dalam mendeterminasi penganutnya dengan nilai-nilai universal-absolut agama. Bahkan melalui otoritas ini dimanfaatkan untuk mengintervensi perkembangan budaya. Bukti intervensi agama ke dalam gerak budaya tergambar dalam ungkapan Nietzsche, "Apa yang ditolak Kristen adalah fakta budaya manusia yang besar". ${ }^{2}$

Kegelisahan Nietzshe terhadap otoritas atas nama agama tersebut kini terasa menembus ruang dan waktu dalam bentuk reinkarnasi ke dalam Dunia Islam. Penyebabnya adalah semakin maraknya dan berkembangnya faham fundamentalisme $e^{3}$-dalam hal ini Fadl Abou al-Fadl menuduh wahabisme sebagai gejala umum dan merupakan contoh kasus yang terlihat dengan jelas- yang memahami Islam terlalu simplistis dan reduksionis yang pada akhirnya menempatkan otoritas mereka -dengan meminjam bahasa Abou al-Fadl- sebagai "Kehendak Tuhan". Pada kesempatan lain Abou al-Fadl mengklaim bahwa gerakan tersebut di era pasca-kolonial lebih membahayakan terhadap warisan kekayaan, keilmuan dan peradaban Islam, daripada kolonialisme. ${ }^{4}$

Sebagai akademisi yang sangat akrab dengan hukum Islam, Abou alFadl mengakui bahwa hukum Islam adalah jantung dan inti dari agama Islam. Dengan mengutip Joseph Schacht, Abou al-Fadl menunjukkan bahwa hukum Islam adalah puncak prestasi peradaban

\footnotetext{
${ }^{1}$ Friedrich Nietzshe, The Joyful Wisdom, trans. Thomas Common (London: NtN Voulis, tt), 167

${ }^{2}$ Nietzshe, The Joyful Wisdom 50.

${ }^{3}$ Memahami Gejala Fundamentalisme," Ulumul Qur'an, Vol. IV No. 3 (1993), 3

${ }^{4}$ Khâled M. Abou el-Fadl, Melawan Tentara Tuban: Yang Berwenang dan Yang Sewenangwenang dalam Islam, terj. Kurniawan Abdullah (Jakarta: PT. Serambi Ilmu Semesta, 2003), $17-38$
} 
Islam. Akan tetapi hukum Islam di hadapan Abou al-Fadl, alih-alih memanjakannya, dia malah tidak percaya bahwa khazanah intelektual itu mampu bertahan dari serbuan trauma kolonialisme dan modernitas. Bahkan, lanjutnya, sisa-sisa khazanah hukum Islam klasik tersebut berada di ambang kepunahan. ${ }^{5}$

Di tengah-tengah kegelisahan tersebut, Abou al-Fadl hendak "menghidupkan kembali" tradisi hukum Islam klasik yang cukup dinamis, dan memiliki basis epistemologi yang toleran dan pluralistik. Jika Muhammed Arkoun mengklaim, bahwa di dalam pemikiran Islam, masih terdapat sesuatu "yang tak dipikirkan", maka, Abou el-Fadl menginginkan penggagasan dan perumusan kembali dalam khazanah pemikiran Islam, yaitu "sesutau yang telah terlupakan". ${ }^{6}$

Melalui "sesuatu yang telah terlupakan" inilah Abou el-Fadl mengajak kita melakukan pembongkaran-pembongkaran terhadap otoritarianisme dalam hukum Islam.

\section{Otoritas Dan Otorotarianisme: Konseptual Teoritis}

Dalam salah satu hasil besutannya Atas Nama Tuban: Dari Fikih Otoriter ke Fikih Otoritatif yang merupakan terjemahan dari Speaking in God's Name: Islamic Law, Authority and Women, Abou el-Fadl menyajikan sebuah kerangka konseptual untuk membangun gagasan tentang otoritas dan otoritarian dalam Islam. Pembahasan otoritas nampaknya sangat penting bagi Abou el-Fadl, karena tanpa otoritas maka yang terjadi adalah beragama secara subjektif, relatif dan individual. Oleh sebab itu perlu ada hal-hal yang baku (al-tsawâbit) dalam agama.

Sebelum mengkaji proses terbentuknya pemegang otoritas dalam Islam sebagaimana dimaksud Abou el-Fadl, ada baiknya memperjelas pemahaman terhadap teoritik otoritas. Secara definitif istilah otoritas sulit dijelaskan karena mengandung ambiguitas dan kompleksitas penggunaan istilah yang ditujukan dalam berbagai jenis aktivitas sosial yang serba ragam. ${ }^{7}$ Namun secara umum sifat dasar otoritas adalah menempatkan kemampuan untuk membuat pihak lain melakukan sesuatu atau tidak melakukan sesuatu sesuai dengan keinginan pihak yang mempunyai otoritas. $^{8}$

\footnotetext{
${ }^{5}$ Khâled M. Abou el-Fadl, Atas Nama Tuhan: Dari Fikih Otoriter ke Fikih Otoritatif, terj. R. Cecep Lukman Yasin (Jakarta: PT. Serambi Ilmu Semesta, 2004), 1.

${ }^{6}$ Abou el-Fadl, Atas Nama Tuban......, 142

${ }^{7}$ April Carter, Otoritas dan Demokrasi, terj. Sahat Simamora (Jakarta: CV. Rajawali, 1985), $1-3$

8 April Carter, Otoritas...., viii
} 
Dalam kaitannnya dengan otoritas Abou el-Fadl membedakan jenisnya, yakni otoritas yang bersifat koersif dan otoritas yang bersifat persuasif. Yang pertama untuk mengarahkan perilaku orang lain dengan cara membujuk, mengambil keuntungan, mengancam, atau menghukum, sehingga orang yang berakal sehat akan berkesimpulan bahwa untuk tujuan praktis mereka tidak punya pilihan lain kecuali harus menurutinya. Sedang yang terakhir melibatkan kekuasaan yang bersifat normatif, yakni kemampuan untuk mengarahkan keyakinan atau prilaku seseorang atas dasar kepercayaan. ${ }^{9}$

Sementara itu meminjam terminologi Richard Friedman, Abou elFadl membedakan antara "memangku otoritas" (being in authority; berada di dalam kekuasaan) dan "memegang otoritas" (being an authority; keberadaan kekuasaan). ${ }^{10}$ Menurut Friedman sebagaimana di langsir Abou el-Fadl, "memangku otoritas" diartikan suatu otoritas didapatkan dengan jabatan struktural dan cenderung memaksa kepada orang lain untuk menerima otoritas tersebut. Dalam kasus ini tidak dikenal adanya "ketundukan atas keputusan pribadi", karena seseorang bisa saja berbeda pendapat dengan yang memangku otoritas, namun tidak memiliki pilihan lain kecuali mentaatinya. Sedangkan "pemegang otoritas" adalah suatu otoritas yang didapatkan tanpa jabatan struktural dan paksaan, melainkan karena kapabilitas dan akseptabilitas seseorang yang akhirnya memunculkan kesadaran orang lain untuk menerimanya.

Secara sintesis Abou el-Fadl menganggap terminologi "memangku otoritas" Friedman tidak lain adalah otoritas koersif, karena orang yang memiliki jabatan struktur ditaati lantaran memiliki kekuasaan yang bersifat memaksa. Sementara otoritas persuasif sejalan dengan makna ungkapan "memegang otoritas", dengan memegang otoritas atau menjadi otoritatif melibatkan unsur kepecayaan, dan setiap prilaku yang dapat memelihara kepercayaan tersebut, termasuk memberikan argumentasi persuasif, akan melanggengkan dan meningkatkan otoritas semacam ini. ${ }^{11}$

Masih menurut Abou el-Fadl, otoritas persuasif atau "pemegang otoritas" tidak melibatkan penyerahan secara total atau penyerahan otonomi tanpa syarat. ${ }^{12}$ Sejalan dengan Abou el-Fadl, dalam pandangan April Carter "pemegang otoritas" memiliki suasana otoritarian terhadap pihak lain (baca: bawahannya), tetapi itu tidak harus menuntut kepatuhan

\footnotetext{
${ }^{9}$ El-Fadl, Atas Nama Tuhan..., 37

${ }^{10}$ El-Fadl, Atas Nama Tuban..., 38

${ }^{11}$ El-Fadl, Atas Nama Tuban..., 42-43

12 Ibid.
} 
mutlak dari pihak lain. Sebab seorang yang mempunyai keahlian pengetahuan (kapabilitas dan akseptabilitas) berada dalam posisi memberi pelayanan kepada pihak lain yang berharap pada ketrampilannya dengan mempertimbangkan urgensinya sehingga terbuka peluang untuk tidak menerima atau mencari alternatif lain. ${ }^{13}$ Dengan bahasa lain, terungkap dalam pernyataan Abou el-Fadl, bahwa "menyejajarkan antara otoritas dengan praktik taklid adalah hal yang tidak masuk akal" tampaknya telah menemukan momentumnya. ${ }^{14}$

Dengan menggunakan teori otoritas tersebut Abou el-Fadl mencoba mengkonstruksi gagasan tentang pemegang otoritas dalam dikursus keIslaman. Dalam konstruksinya konsep otoritas Islam sebagi wujud menjembatani kehendak Tuhan, Abou el-Fadl memperhatikan tiga hal berikut: Pertama berkaitan dengan "kompetensi" (autentisitas). Kedua, berkaitan dengan "penetapan makna". Ketiga berkaitan dengan "perwakilan". Tiga pokok persoalan inilah menurut Abou elFadl, memainkan peranan penting dalam membentuk "pemegang otoritas" dalam dikursus keislaman.

Menempatkan otoritas dalam diskursus keislaman bukan tanpa persoalan, karena dengan sikap kesewenang-wenangan terhadap gagasan otoritas akan menggiring pada sikap otoritiarianisme. Dengan demikian ini menyiscayakan gagasan otoritas di satu sisi akan saling berhadapan dengan sikap otoritarianisme di sisi lain.

Otoritarianisme menurut Abou el-Fadl, adalah "tindakan mengunci dan mengurung kehendak. Tuhan atau kehendak teks, dalam sebuah penetapan makna, dan kemudian menyajikan penetapan tersebut sebagi sesuatu yang pasti, absolut, dan menentukan". ${ }^{15}$ Otoritarianisme juga ditandai dengan penyatuan pembaca dengan teks. Sehingga penetapan pembaca itu akan menjadi perwujudan eksklusif teks tesebut. Akibatnya teks dan konstruksi pembaca akan menjadi satu dan serupa. Dalam proses ini teks tersebut akan tunduk kepada pembaca dan secara efektif pembaca menjadi pengganti teks. ${ }^{16}$ Dengan demikian pembaca hanya akan melahirkan penafsiran yang otoriter. Lebih jauh lagi melahirkan fanatisme yang mengkultuskan pada penafsiran-penafsiran itu sehingga menganggap hasil penafsirannya memiliki kompetensi (autentisitas) yang sama dengan teks asal (Al-Qur'an dan al-sunnah).

\footnotetext{
${ }^{13}$ Carter, Otoritas....., 31

${ }^{14}$ El-Fadl, Atas Nama Tuban..., 40

${ }^{15}$ El-Fadl, Atas Nama Tuban..., 50

${ }^{16}$ El-Fadl, Atas Nama Tuban..., 138.
} 
Dalam posisi seperti ini, maka secara realitas ontologis Tuhan pergerakan ontoritarianisme telah mengambil alih kehendak Tuhan oleh wakil Tuhan. Perbedaan antara wakil dan Tuannya menjadi tidak jelas dan kabur. ${ }^{17}$ Ujungnya pernyataan antara seorang wakil dan kehendak Tuhan menjadi satu dan serupa.

Dalam dataran subyektifitas penafsiran ditegaskan oleh Abou el-Fadl, bahwa semua penafsiran terdapat kecenderungan yang pasti mengarah kepada otoritarianisme. Yang ditandai dengan "penetapan makna yang bersifat tetap dan tidak bisa berubah." Bagi Abou el-Fadl, lagi-lagi dalam pengertian ini, moralitas tertinggi adalah moralitas diskursusnya, bukan semata ketetapannya. Dalam konteks otoritarianisme, gagasan tentang "teks terbuka" sangat membantu untuk memahami pemikiran Abou el-Fadl. Al-Qur'an dan sunnah baginya adalah karya yang membiarkan dirinya terbuka bagi strategi penafsiran.

Abou el-Fadl menambahkan, bahwa dalam penetapan makna terdapat proses dialektika yang tidak akan pernah final, sebaliknya penafsiran yang otoriter akan menganut sebuah tesis bahwa ia akan tiba pada sebuah kebenaran akhir, atau akan mencapai sebuah sintesis bahwa ia mesti dipandang final dan tidak bisa berubah. ${ }^{18}$ Dengan ungkapan lain, proses penafsiran otoriter ini percaya bahwa ia mendengar firman Tuhan dengan jelas dan lugas, serta bebas dari ambiguitas. Seandainya penafsiran otoriter ini sepenuhnya terlibat dalam proses dialektika, maka ia akan memperpendek proses tersebut. Sekali lagi, teks memiliki spektrum yang luas. Selalu ada ketegangan antara teks dan representasinya.

\section{Gagasan Hermeneutika}

Terobosan terpenting yang disajikan oleh Abou el-Fadl dalam usahanya menggali "sesuatu yang telah terlupakan" adalah mengembalikan jati diri otoritas keagamaan (baca: "kompetensi autentisitas-", "penetapan makna", "perwakilan") dari sikap otoritarianisme dengan melawan paksa upaya penaklukan dan penutupan teks oleh pembaca. Baginya, teks tetap bebas, terbuka, dan otonom. Ide yang sama juga pernah disampaikan oleh Farid Esack dengan memahami Al-Qur'an sebagai “pewahyuan progresif". ${ }^{19}$ Maka dari itu, untuk menghindari sikap otoriter adalah tetap sadar bahwa teks (Al-Qur'an) merupakan "karya

\footnotetext{
${ }^{17}$ El-Fadl, Atas Nama Tuhan..., 205.

18 El-Fadl, Melawan......, 54

${ }^{19}$ Farid Esack, Membebaskan Yang Tertindas, terj. Watung A. Budiman (Bandung: Mizan, 2000), 87.
} 
yang terus berubah" atau "wahyu yang progresif". Sehingga segala bentuk penafsiran dan pemahaman akan terus aktif, dinamis dan progresif.

Tentu saja untuk usaha tersebut perlu perangkat tepat yang digunakan sebagai pisau analisisnya. Dalam hal ini perangkat yang digunakan Abou el-Fadl lebih kepada apa yang dinamakan dengan bermenentika.

\section{Penetapan Makna: Teks, Tradisi dan Asumsi (Pra-sangka)}

Manusia di hadapan teks adalah 'lidab' sebagai artikulatur sekaligus interpreter teks. Memposisikan manusia dalam subjek teks, bukan tanpa masalah, malah sebaliknya. Karena tidak jarang, kita jatuh pada "pembunuhan teks" dan "pelacuran hermeneutika" yang merampas kesucian (autentisitas) teks. Ketika semua berhak menafsirkan dengan teks tanpa kewewenangan, tidak ada yang bisa menjamin teks tersebut ditafsirkan sebebas-bebasnya. Dalam posisi ini, teks akan ditelanjangi dari autentitas, makna dan tujuannya. Dalam pandangan Abou el-Fadl, sikap tersebut merupakan tindakan sewenang-wenang yang menyuburkan penafsiran otoriter.

Menurut Abou el-Fadl untuk menjaga otentisitas teks dia menjawab persoalan ini kita membutuhkan keseimbangan kekuatan yang harus ada antara maksud teks, pengarang dan pembaca (balance of power between the author, reader and text). Penetapan makna berasal dari proses yang kompleks, interaktif, dinamis dan dialektis antara ketiga unsur di atas (teks, pengarang dan pembaca). Salah satu maksud tiga unsur itu tidak ada yang mendominasi. Penafsiran yang tepat adalah penafsiran yang menghormati peranan, otonomi dan integritas teks.

Pertanyaan selanjutnya adalah, ketika teks memiliki otonomi dan makna tersendiri sedangkan pembaca juga membawa subjektifitas yang bisa melahirkan makna lain, bagaimana relasi dialektis dua makna tersebut? Abou el-Fadl tidak menjelaskan lebih lanjut, dia hanya memberikan kaidah "perimbangan kekuatan" antara pengarang yang diwakili teks dengan pembaca.

Selain persoalan penetapan makna tersebut, Abou el-Fadl juga memaparkan persoalan penting lain yaitu persoalan pembuktian yang mendasari pengambilan kesimpulan hukum. Pembuktian itu terkait dengan "asumsi dasar" dalam komunitas penafsiran. Ada empat asumsi dasar yang berfungsi sebagai landasan untuk membangun analisis hukum. Yaitu, asumsi berbasis nilai, asumsi metodologis, asumsi berbasis iman, dan asumsi berbasis akal. 
Asumsi berbasis nilai dibangun di atas nilai-nilai normatif yang dipandang penting atau mendasar oleh sebuah sistem hukum. Misalnya nila-nilai dalam perbedaan dharûriyat, bâjiyat, dan tabsinât. Asumsi metodologis terkait dengan sarana atau langkah yang diperlukan untuk mencapai tujuan normatif hukum. Perbedaan antara madzhab hukum dipandang sangat bersifat metodologis. Sedangkan asumsi berbasis akal berdasar pada potongan-potongan bukti yang bersifat kumulatif, sebagai hasil dari proses objektif dalam mempertimbangkan berbagai bukti secara rasional, bukan hasil dari pengalaman etis, eksistensial, atau metafisik yang bersifat pribadi. Sedangkan asumsi berbasis iman bukan berasal dari klaim diperoleh dari perintah Tuhan, tapi dinamika antara manusia (wakîi) dan Tuhan. Asumsi berbasis iman dibangun di atas pemahaman-pemahaman pokok atau mendasar tentang karakteristik pesan Tuhan dan tujuannya. ${ }^{20}$

\section{Pelaku Hermeneutika dan Prinsip-prinsip Interprestasi: Kasus Islam}

Gagasan Abou El-Fadl tentang pelaku bermeneutika dalam Islam adalah menarik untuk memahami gagasan Qur'anik-nya. Pada beberapa kesempatan, Al-Qur'an merujuk pada fakta bahwa Tuhan telah menciptakan manusia sebagai khaliffah di muka bumi. Khaliffah bisa berarti pewaris, wakil atau pelaksana, tetapi gagasan dasarnya adalah bahwa manusia diciptakan sebagai wakil Tuhan di bumi. ${ }^{21}$ Kehendak Tuhan yang termanifestasikan dalam Kedaulatan Tuhan tidak akan menegasikan kewakilan manusia, justru sebaliknya, mengakomodasi kewakilan manusia dan akan menaikkan derajat mereka sebagai sebuah kontribusi mereka atas penjagaan dan penegakan hukum Tuhan di muka bumi ini.

Meskipun manusia dipandang sebagai pelaksana kehendak Tuannya, sebenarnya mereka sebagai pelaksana tidak sepenuhnya bebas, karena terikat dengan seperangkat instruksi yang dikeluarkan Tuannya. Mereka tidak boleh bertindak melampui mandat ini. ${ }^{22}$ Petunjuk untuk mengetahui Kehendak Tuhan adalah dalîlyang akan menjadi petunjuk, pemandu, tanda atau bukti mengenai Kehendak Tuhan. Pada garis ini, ditegaskan bahwa Tuhan tidak mengharapkan sebuah kebenaran yang obyektif atau tunggal. Tuhan menginginkan agar manusia mencari dan menemukan Kehendak Tuhan. Kebenaran adalah pencarian itu sendiri -

\footnotetext{
${ }^{20}$ El-Fadl, Atas Nama Tuban..., 227-231

${ }^{21}$ El-Fadl, Atas Nama Tuban..., 37-40

22 Ibid.
} 
pencarian itu sendiri adalah kebenaran yang tertinggi. Oleh karena itu, hasil dari pencarian itu diukur berdasarkan ketulusan seseorang dalam melakukan pencarian

Karena umat manusia bukan penerima komunikasi yang langsung dan personal dari Tuhan, maka seseorang harus menyelidiki Kehendak Tuhan melalui suatu medium.Medium atau dalîl untuk mengetahui, memahami dan menjalankan Kehendak Tuhan sangat beragam -seperti yang telah diperdebatkan oleh umat Islam dan para islamisist selama-selama berabadabad, yang di antaranya adalah akal dan nalar ('aqlu dan ra'yu), intuisi (fitrah), kebiasaan dan praktik manusia ('urf dan 'âdah), dan teks (nas).

Sebagian wakil (orang-orang Islam yang beriman dan shaleh, yang di sebut sebagai wakil umum) menundukkan keinginannya dan menyerahkan sebagian keputusannya kepada sekelompok orang atau wakil dari golongan tertentu ("ulamâ). Mereka melakukan hal tersebut "karena, dan hanya karena," mereka memandang wakil dari golongan tertentu memiliki otoritas. Kelompok khusus ini menjadi otoritatif karena dipandang memiliki kompetensi dan pemahaman yang khusus terhadap perintah atau kehendak Tuhan. Kelompok khusus (disebut dengan wakil khusus) ini dipandang otoritatif "bukan karena mereka memangku otoritas" ${ }^{23}$-jabatan formal tidak relevan sama sekali- tetapi karena persepsi wakil umum menyangkut otoritas mereka berkaitan dengan seperangkat perintah (petunjuk) yang mengarah pada Jalan Tuhan. Proses penyerahan keputusan untuk mengetahui dan memahami kehendak Tuhan, dari wakil umum kepada wakil khusus juga memiliki problem bermeneutis tersendiri misalnya, pada proses tindak komunikasi dan dialog di antara keduanya.

Sampai di sini, dapat kita tarik sebuah pemahaman, bahwa kerja bermeneutika dalam kasus Islam, memiliki beberapa subyek, yang antara lain Tuhan, medium (teks dan lainnya), dan manusia (yang terbagi ke dalam wakil khusus dan wakil umum). Selain itu dapat ditegaskan pula bahwa kehendak Tuhan terwujud sebagai kedaulatan Tuhan yang diekspresikan melalui berbagai medium, salah satunya adalah teks.

Manusia sebagai wakil Tuhan berkewajiban untuk merealisasikan Kedaulatan Tuhan tersebut di muka bumi ini, dengan mengetahui dan memahami Kehendak Tuhan melalui berbagai medium, tetapi sebagai medium yang terpenting adalah teks. Dalam proses pemahaman terhadap teks muncullah problem hermeneutis, pada tingkat pertama. Wakil Tuhan terbagi menjadi dua kategori, wakil umum dan wakil khusus. Di mana yang pertama menyerahkan tugas mencari dan mengetahui kehendak Tuhan

\footnotetext{
${ }^{23}$ Ibid.
} 
kepada yang terakhir, lagi-lagi di sini juga memunculkan problem bermeneutis tersendiri.

Menarik untuk ditambahkan bahwa dalam melakukan pelimpahan otoritas wakil khusus dan untuk menghindari penyelewengan otoritas tersebut, Abou el-Fadl mengajukan "lima syarat keberwenangan" yang harus dipenuhi wakil khusus ketika ia menerima otoritas yang diberikan wakil umum dan agar wakil kbusus tidak menyelewengkannya.

Uraiannya adalah sebagai berikut; Pertama, kejujujuran (bonesty), memiliki kejujuran, dapat dipercaya untuk menjadi wakil dalam memahami perintah Tuhan. Kedua, Kesungguhan (diligence), mengerahkan segenap upaya rasional dalam menemukan dan memahami Kehendak Tuhan. Ketiga kemenyeluruhan (comprehensiveness), melakukan penyelidikan secara menyeluruh untuk memahami Kehendak Tuhan. Keempat, rasionalitas (reasonableness) melakukan upaya penafsiran dan menganalisis perintah-perintah Tuhan secara rasional. Kelima pengendalian diri (selfrestraint) memiliki kerendahan hati dan pengendalian diri dalam menjelaskan Kehendak Tuhan. ${ }^{24}$

Seorang wakil harus memiliki kewaspadaan untuk menghindari penyimpangan atas peran Tuhan, berarti dia harus mengenal batasan peran yang menjadi haknya saja. Seorang wakil khusus jika tidak memiliki syarat di atas maka akan mudah melakukan pemahaman dan tindakan yang otoriter dengan mengatasi namakan Tuhan.

\section{Kontribusi Bagi Pengembangan Ilmu pengetahuan}

Tampaknya pemikiran Abou el-Fadl menganut paham "relativitas". Bukan tanpa alasan Abou el-Fadl menganut pemikiran relativitas, sebaliknya pemikiran seperti ini inspirasinya justru termuat dalam "normativitas dan historisitas". 25

Hal ini terlihat bagaimana Abou el-Fadl menolak ketika seseorang telah menemukan maksud pengarang, karena hal itu tidak mungkin, yang disebabkan oleh berbagai faktor yang melingkupinya, tradisi, karakteristik teks, pembaca dan situasi historis. Secara tidak langsung, dia telah menyatakan "niat awal dari penulis sudah tidak lagi digunakan sebagai acuan utama dalam memahami teks".

\footnotetext{
${ }^{24}$ El-Fadl, Atas Nama Tuban..., 97-101

25 Amin Abdullah, "Pendekatan Hermeneutik dalam Studi Fatwa-fatwa Keagamaan: Proses Negosiasi Komunitas Pencari Makna, Pengarang dan Pembaca,” dalam Khâled M. Abou elFadl, Atas...., vii-xvii
} 
Yang terpenting adalah bahwa tawaran hermeneutika Abou elFadl, yang digagas dari paradigma hukum Islam dalam konstruksinya tentang hermeneutika tidak hanya aplikatif dalam penafsiran Al-Qur'an, tapi juga pada teks-teks Islam yang lain. Dengan kata lain, Abou el-Fadl telah mencoba melakukan rancang bangun bermeneutika yang dapat menjadi prinsip-prinsip umum dalam menafsirkan teks-teks Islam (baik yang sakral maupun yang profan).

Hal ini belum dilakukan oleh para pemikir Islam kontemporer, yang masih berkutat pada hermeneutika Al-Qur'an -hermenentika khusus-. Selain itu dia telah menyumbangkan beberapa konsep yang berharga bagi pengembangan hermeneutik Al-Qur'an, sebagai contoh adalah bagaimana ia menggagas secara radikal konsep tentang negosiasi makna yang melibatkan tiga unsur, teks, pengarang dan pembaca. Lagi-lagi hal ini belum banyak hermeneut Muslim yang menteorisasikannya. Sebagai seorang ahli hukum, sangat mencengangkan bagaimana ia menerima konsep pra-sangka berupa persepsi, keadaan, dan latar belakang dari seseorang yang membuat penafsiran) yang kemudian menggiringnya pada subyektifitas setiap penafsiran, termasuk dalam proses penetapan hukum, alih-alih dia menemukan keunikan dan kekhasannya. ${ }^{26}$ Selain penerimaannya terhadap pra-sangka, ia juga sangat memperhatikan konstruksi tradisi yang terus berkembang.

\section{Kesimpulan}

Kegelisahan yang dirasakan Abou el-Fadl -begitu juga dengan para akademika yang lain- tidak lepas dari serbuan gerakan fundamentalis yang menyerukan kembali kepada "fundamentals" (dasar-dasar) agama secara "penuh" dan "literal," bebas dari kompromi, penjinakan dan reinterpertasi. Sebuah gerak yang sebernarnya justru telah mengkudeta otoritas. Meinstrem otoritas sendiri bagi Abou el-Fadl sangat penting, sebab tanpa otoritas yang terjadi adalah beragama secara subjektif, relatif dan individual. Akan tetapi menempatkan otoritas, yang dalam hal ini berkaitan dengan "kompetensi -autentisitas-", "penetapan makna", "perwakilan" tentu bukan tanpa persoalan, karena dengan sikap kesewenang-wenangan terhadap gagasan otoritas akan menggiring pada sikap otoritarianisme.

Pada ranah otoritarianisme akan terjadi tindakan mengunci dan mengurung kehendak Tuhan atau kehendak teks, dalam sebuah

\footnotetext{
${ }^{26}$ Khaled Abou El Fadl, Cita dan Fakta Toleransi dalam Islam: Puritanisme Versus Pluralisme, terj. Heru Prasetia (Bandung: Arasy, 2003), 74-78
} 
penetapan makna, dan menyajikannya sebagai sesuatu yang pasti, absolut, dan menentukan. Dihadapkan adanya sikap otoritarianisme tersebut Abou el-Fadl melawan paksa upaya penaklukan dan penutupan teks sekaligus memandang teks tetap bebas, terbuka, dan otonom guna memahami dan mendekati kehendak Tuhan. Dengan mengispirasikan teks tetap bebas, terbuka, dan otonom sebagai kehendak Tuhan, maka Abou elFadl menempatkan perangkat yang akan mengantarkan kepada sebuah pemahaman untuk mendekati kehendak Tuhan. Dalam hal ini adalah gagasan-gagasan yang selama ini menjadi problem hermeneutis. Dan itulah yang telah menjadi gagasan Abou el-Fadl.

Adapun gerak heremenutika tersebut antara lain adalah membutuhkan "keseimbangan kekuatan" yang harus ada antara maksud teks, pengarang dan pembaca. Dengan kata lain, penetapan makna berasal dari proses yang kompleks, interaktif, dinamis dan dialektis antara ketiga unsur di atas (teks, pengarang dan pembaca). Sementara itu seorang pembaca/ penafsir -dalam hal ini wakil khusus- dalam membaca teks agar tidak terjadi penyelewengan otoritas harus memenuhi "lima syarat keberwenangan" sebagai prinsip-prinsip penafsiran yang "bertanggung jawab”. Antara lain, kejujujuran, kesungguhan, kemenyeluruhan, rasionalitas, dan pengendalian diri. Pada persoalan lain, kenyataan bahwa pembaca/penafsir tidak bebas asumsi, maka dalam menafsirkan terkadang bertentang dengan teks. Dalam kondisi semacam ini pembaca/ penafsir harus melakukan jeda ketelitian terhadap teks. Maksud dari jeda ini bukan untuk menampik teks atau menolak penetapan tersebut, tapi untuk merenungkan dan menyelidikinya secara lebih mendalam lagi. Ini serupa dengan menggaris bawahi sebuah persoalan untuk kemudian mengkajinya lebih lanjut, dan menangguhkan keputusan hingga kajian tersebut rampung. 


\section{Daftar Pustaka}

Abdullah, Amin. "Pendekatan Hermeneutik dalam Studi Fatwa-fatwa Keagamaan: Proses Negosiasi Komunitas Pencari Makna, Pengarang dan Pembaca," dalam Khâled M. Abou el-Fadl, Atas Nama Tuban: Dari Fikih Otoriter ke Fikih Otoritatif, terj. R. Cecep Lukman Yasin Jakarta: PT. Serambi Ilmu Semesta, 2004.

Azra, Azyumardi, "Memahami Gejala Fundamentalisme," dalam Ulûmu alQur'an, Vol. IV No. 31993

Bleicher, Josefk. Hermenentika Kontemporer: Hermeneutika Sebagai Metode, Filsafat Dan Kritik. terj. Ahmad Norma Permata. Yogyakarta: Fajar Pustaka Baru, 2003.

Carter, April. Otoritas dan Demokrasi. terj. Sahat Simamora. Jakarta: CV. Rajawali, 1985.

El-Fadl, Khâled M. Abou. Atas Nama Tuban: Dari Fikih Otoriter ke Fikih Otoritatif. terj. R. Cecep Lukman Yasin. Jakarta: PT. Serambi Ilmu Semesta, 2004.

. Melawan Tentara Tuban: Yang Berwenang dan Yang Sewenang-wenang dalam Islam. terj. Kurniawan Abdullah. Jakarta: PT. Serambi Ilmu Semesta, 2003.

Nietzshe, Friedrich. The Joyful Wisdom. trans. Thomas Common. London: $\mathrm{NtN}$ Voulis, t.t. 